\title{
Effect of postoperative positive airway pressure on risk of postoperative atrial fibrillation after cardiac surgery in patients with obstructive sleep apnea: a retrospective cohort study
}

\author{
Feihong Ding ${ }^{1}$, Jimmy Kar-Hing Wong ${ }^{2}$, Alice S. Whittemore ${ }^{3}$ and Clete A. Kushida ${ }^{*^{*}}$
}

\begin{abstract}
Background: Obstructive sleep apnea (OSA) is a known risk factor for postoperative atrial fibrillation (POAF) after cardiac surgery. However, whether better management of OSA reduces the risk of POAF remains unknown. The aim of this study was to determine if postoperative positive airway pressure (PAP) treatment for OSA reduces POAF risk after cardiac surgery. PAP included both continuous and bilevel positive airway pressure.

Methods: This retrospective cohort study was conducted at Stanford University teaching hospital. We included a total of 152 OSA patients with preoperative electrocardiography showing sinus rhythm who underwent coronary artery bypass grafting (CABG), aortic valve replacement, mitral valve repair/replacement, or combined valve and CABG surgery from October 2007 to September 2014. Postoperative PAP use status was determined by reviewing electronic health records. The primary outcome was time to incident POAF. We reviewed records from the time of surgery to hospital discharge. Multivariate Cox regression model was used to calculate the adjusted hazard ratio of postoperative PAP in association with risk of POAF.

Results: Of the 152 OSA patients included for analysis, 86 (57\%) developed POAF, and 76 (50\%) received postoperative PAP treatment. POAF occurred in 37 (49\%) of the patients receiving postoperative PAP, compared with $49(65 \%)$ of those not receiving postoperative PAP (unadjusted $p$ value $=0.33$ ). Multivariable Cox regression analysis of time to incident POAF did not show an association between postoperative PAP treatment and risk of POAF (adjusted hazard ratio: 0.93 [95\%Cl: $0.58-1.48]$ ). There were no significant differences in other postoperative complications between the two groups.
\end{abstract}

Conclusions: The study did not find an association between postoperative PAP treatment and risk of POAF after cardiac surgery in patients with OSA. Future prospective randomized trials are needed to investigate this issue further.

Keywords: Obstructive sleep apnea, Positive airway pressure, Postoperative atrial fibrillation, Cardiac surgery

\footnotetext{
* Correspondence: clete@stanford.edu

${ }^{1}$ Division of Sleep Medicine, Department of Psychiatry and Behavioral

Sciences, Stanford Sleep Medicine Center, 450 Broadway Street, MC 5704,

Pavilion C, 2nd Floor, Redwood City, CA 94063-5704, USA

Full list of author information is available at the end of the article
} 


\section{Background}

Postoperative atrial fibrillation (POAF) is a common complication following cardiac surgery, affecting 30\% to $50 \%$ of patients (Yadava et al. 2014). Although generally welltolerated and self-resolving, POAF is associated with multiple adverse outcomes: increased risk of stroke, increased short- and long-term mortality, prolonged hospitalizations, increased cost of care, and late recurrence of atrial fibrillation (Horwich et al. 2013; Phan et al. 2015; LaPar et al. 2014; Ahlsson et al. 2010). Multiple risk factors-including advanced age, previous atrial fibrillation, valve surgery, chronic obstructive pulmonary disease, and perioperative withdrawal of beta-blockers-are associated with POAF after cardiac surgery (Mathew et al. 2004), but few are modifiable. Several studies have shown that obstructive sleep apnea (OSA), with an estimated prevalence of up to $80 \%$ in the cardiac surgical population (Zhao et al. 2015), is an independent risk factor for POAF (Zhao et al. 2015; Wong et al. 2015; Uchôa et al. 2015; van Oosten et al. 2014; Qaddoura et al. 2014). However, whether OSA is a modifiable risk factor for POAF after cardiac surgery is unknown.

The most effective OSA treatments are continuous positive airway pressure (CPAP) or bilevel positive airway pressure (BPAP) (the term "positive airway pressure" or PAP denotes either CPAP or BPAP in this study). In nonsurgical OSA patients, PAP therapy has been shown to reduce the recurrence rate of atrial fibrillation (Qureshi et al. 2015). However, no studies have investigated the effect of postoperative PAP on POAF after cardiac surgery. Given the poor adherence to PAP treatment of OSA patients at home (Stepnowsky \& Moore 2003), the postoperative period after cardiac surgery may provide an ideal opportunity for physicians to use PAP to reduce the risk of POAF in OSA patients. Therefore, this retrospective cohort study aimed to determine if postoperative PAP reduces POAF risk after cardiac surgery in OSA patients.

\section{Methods \\ Study population}

We included OSA patients who underwent coronary artery bypass grafting (CABG), aortic valve replacement, mitral valve replacement/repair, or combined valve and CABG surgery requiring cardiopulmonary bypass performed at Stanford University from October 2007 to September 2014. We reviewed electronic medical charts of consecutive patients. Cardiac parameters including atrial fibrillation history and POAF, and sleep-related data including OSA history and post-operative PAP use were reviewed by two different investigators. We considered patients to have OSA if: 1) two independent sources documented a prior diagnosis of OSA, 2) one source documented a prior diagnosis of OSA with explicit documentation of whether the patient was using nocturnal PAP, or 3) a sleep study in the medical record documented OSA (Wong et al. 2015). We considered patients to have received postoperative PAP

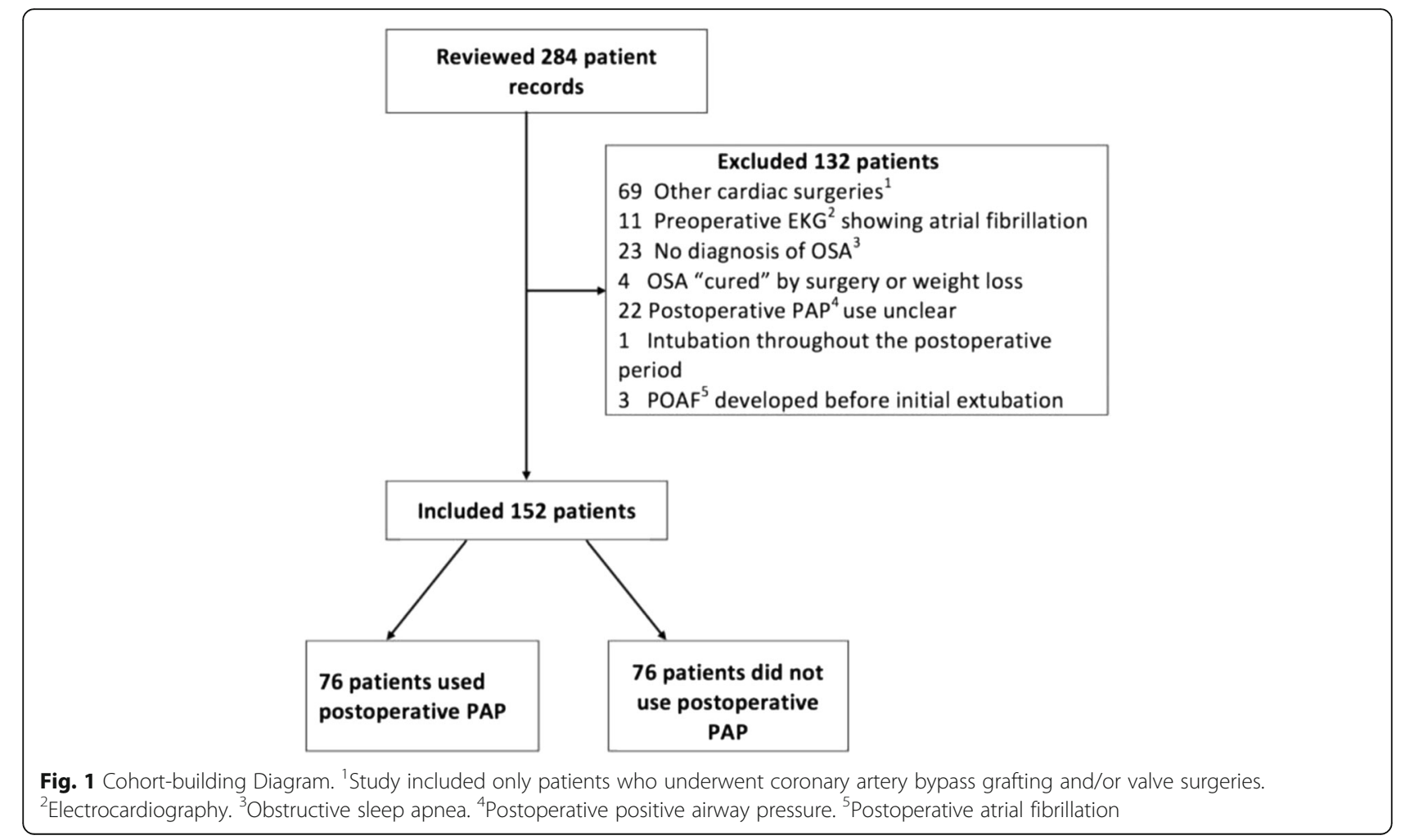


Table 1 Descriptive Characteristics of the Study Groups, mean \pm S.D. or $\mathrm{N}(\%)$

\begin{tabular}{|c|c|c|c|}
\hline Characteristics & $\begin{array}{l}\text { No Postoperative } \\
\text { PAP }\end{array}$ & $\begin{array}{l}\text { Postoperative } \\
\text { PAP }\end{array}$ & $p$ value $^{b}$ \\
\hline N & $76(50)$ & $76(50)$ & \\
\hline Age (yrs.) & $67.3 \pm 10.4$ & $63.7 \pm 12.1$ & 0.05 \\
\hline Male & $53(69.7)$ & $64(84.2)$ & 0.03 \\
\hline White & $53(69.7)$ & $56(73.7)$ & 0.59 \\
\hline Body Mass Index $\left(\mathrm{kg} / \mathrm{m}^{2}\right)$ & $32.1 \pm 7.6$ & $32.1 \pm 7.1$ & 0.99 \\
\hline \multicolumn{4}{|l|}{ Comorbidities } \\
\hline Previous Atrial Fibrillation & $16(21.1)$ & $16(21.1)$ & 1.00 \\
\hline $\begin{array}{l}\text { Previous Cerebrovascular } \\
\text { Event }^{c}\end{array}$ & $13(17.1)$ & $5(6.6)$ & 0.05 \\
\hline $\begin{array}{l}\text { Previous Myocardial } \\
\text { Infarction }\end{array}$ & $16(21.1)$ & $6(7.9)$ & 0.02 \\
\hline $\operatorname{COPD}^{d}$ & $11(14.5)$ & $5(6.6)$ & 0.11 \\
\hline Hypertension & $63(82.9)$ & $59(77.6)$ & 0.42 \\
\hline Hyperlipidemia & $50(65.8)$ & $51(67.1)$ & 0.86 \\
\hline \multicolumn{4}{|l|}{ Perioperative Characteristics } \\
\hline Elective Surgery & $69(90.8)$ & $67(88.2)$ & 0.60 \\
\hline Valve Surgery & $44(57.9)$ & $47(61.8)$ & 0.62 \\
\hline Preoperative $\mid A B P^{e}$ & $2(2.6)$ & $0(0)$ & 0.50 \\
\hline CPB time ${ }^{f}$ (mins) & $153.9 \pm 59.3$ & $174.4 \pm 79.7$ & 0.07 \\
\hline $\begin{array}{l}\text { Aortic Cross-Clamp } \\
\text { time (mins) }\end{array}$ & $103.9 \pm 44.7$ & $121.2 \pm 62.3$ & 0.05 \\
\hline $\begin{array}{l}\text { Post operative day } \\
\text { of extubation }\end{array}$ & $0.5 \pm 0.8$ & $0.6 \pm 1.0$ & 0.68 \\
\hline Home PAP use & $17(22.4)$ & 62 (81.6) & $<0.0001$ \\
\hline
\end{tabular}

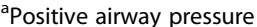

${ }^{\text {b }}$ Student $\mathrm{t}$ tests, Chi-square tests or Fisher's exact tests were used to calculate the $p$ value

${ }^{c}$ Cerebrovascular Event includes cerebral vascular accident and transient ischemic attack

${ }^{\mathrm{d} C h r o n i c ~ o b s t r u c t i v e ~ p u l m o n a r y ~ d i s e a s e ~}$

e Intra-aortic balloon counterpulsation pump

${ }^{\mathrm{f}}$ Cardiopulmonary bypass time

if: 1) progress notes or sleep prescriptions explicitly documented use of nocturnal PAP after extubation and before the onset of POAF; and 2) follow-up documentation confirmed PAP use at least one night before hospital discharge.

\section{Primary outcome}

The primary outcome was time to incident POAF. We defined POAF as atrial fibrillation requiring either pharmacologic treatment or direct current cardioversion after initial extubation from cardiac surgery and before discharge from hospital. We determined the timing of POAF by reviewing physicians and nurses' notes, pharmacy records, procedural notes, electrocardiography (EKG) and telemetry strips. All cardiac surgery patients were on telemetry monitoring for their entire hospitalization.

\section{Statistical analysis}

We tested differences in demographic variables, comorbidities, and perioperative characteristics using t-tests for continuous variables and chi-square tests or Fisher's exact tests for categorical variables. All tests were two-tailed. We considered variables to be statistically significant if they attained a $\mathrm{p}$ value of $<0.05$.

We treated postoperative PAP treatment as a time dependent variable in a multivariate Cox regression model. Because we lacked data on intermittent postoperative PAP use, we assumed that PAP treatment continued until discharge once it started. The regression model included covariates that differed in bivariate analyses $(\mathrm{p} \leq 0.1)$ or that had previously been identified as potential confounders. We checked the proportional hazard assumption with loglog plots. All statistical analyses were performed using SAS version 9.4 (SAS Institute, Cary, NC).

This retrospective cohort study was approved by our Institutional Review Board. The requirement to obtain individual consent was waived because the data were collected retrospectively.

\section{Results}

We reviewed a total of 284 patient records. After excluding 132 patients for various reasons (Fig. 1), there were 152 patients eligible for study. Exactly half of the 152 eligible patients $(N=76)$ received postoperative PAP treatment.

Home PAP use was a strong predictor for postoperative PAP treatment (Table 1). 62 patients (82\%) among those who received postoperative PAP had used PAP at home preoperatively, compared with 17 patients (22\%) among those who did not receive postoperative PAP. Compared with patients who did not receive postoperative PAP, patients who received postoperative PAP were younger, more likely to be male, had a significantly lower proportion of preoperative comorbidities including history of cerebrovascular events and myocardial infarction, and had a significantly longer cardiopulmonary bypass time and aortic cross-clamp time. As shown in Table 1, we observed no differences between the two groups in body mass index, previous atrial fibrillation, or postoperative day of extubation.

Among patients who received postoperative PAP treatment, 33 (43\%) started treatment immediately on the day of cardiac surgery, and 55 patients (72\%) started within the first day after surgery. The remaining patients started postoperative PAP on postoperative day 2 to day 10 (Fig. 2a).

Eighty-six patients (57\%) developed POAF after cardiac surgery. The majority of POAF cases occurred in the 3day period from postoperative day 2 to day 4 , with a peak incidence on day 2. POAF occurred slightly later among patients who received postoperative PAP than that among those who did not, but the difference was not statistically significant (Fig. 2b). 


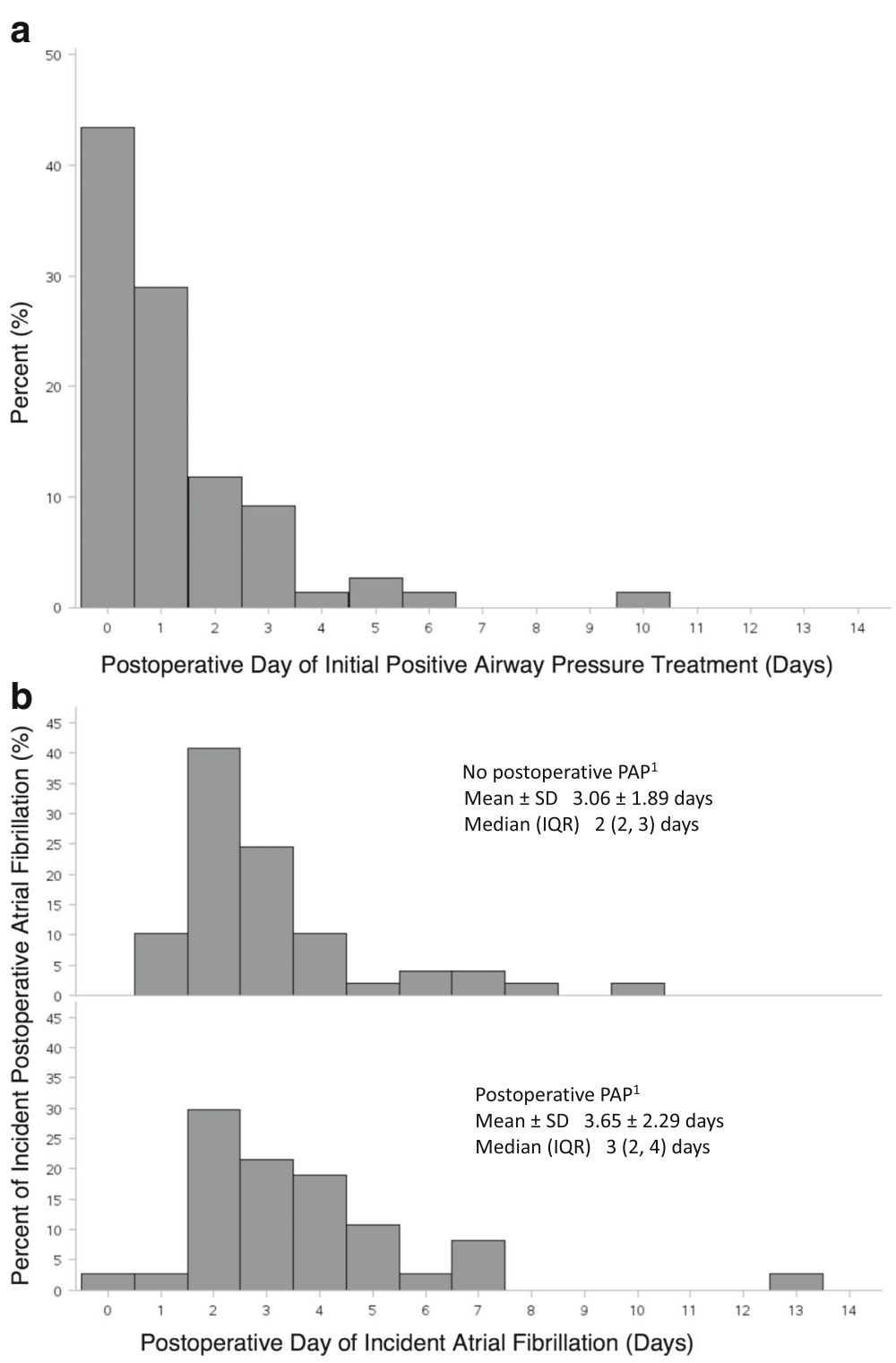

Fig. 2 a Distribution of Postoperative Day of Initial Positive Pressure Airway Treatment Among 76 Patients. b Distribution of Postoperative Day of Incident Atrial Fibrillation. ${ }^{1} p=0.20$ for test of no difference in days of incident postoperative atrial fibrillation

Figure 3 shows a forest plot of hazard ratios and 95\% confidence intervals obtained from a multivariable Cox regression model. Thirty-seven (49\%) of the 76 patients receiving postoperative PAP treatment developed POAF, compared with $49(65 \%)$ of the 76 patients without postoperative PAP treatment. As seen in Fig. 3 and Table 2, analysis of time to incident POAF did not show an association between postoperative PAP treatment and POAF risk (adjusted hazard ratio: 0.93 [95\% CI: $0.58-1.48]$ ). In contrast, we observed a significant increase in POAF risk among older patients (adjusted hazard ratio for 10year increase in age: 1.30 [95\% CI: $1.04-1.61]$ ) and those with a prior history of atrial fibrillation (adjusted hazard ratio: 2.34 [95\% CI: $1.42-3.86]$ ).
We did not find an effect of postoperative PAP treatment on other postoperative complications such as reintubation, ICU readmission, length of initial ICU stay or hospital stay (Table 3).

\section{Discussion}

POAF remains a common complication after cardiac surgery. Multiple risk factors have been identified, but few are modifiable. We hypothesized that PAP after cardiac surgery reduces the risk of POAF in patients with OSA.

OSA has been associated with increased risk of POAF after cardiac surgery. Several pathophysiologic mechanisms may contribute to the relationship between OSA and atrial fibrillation: sudden and repeated swings in intra-thoracic 


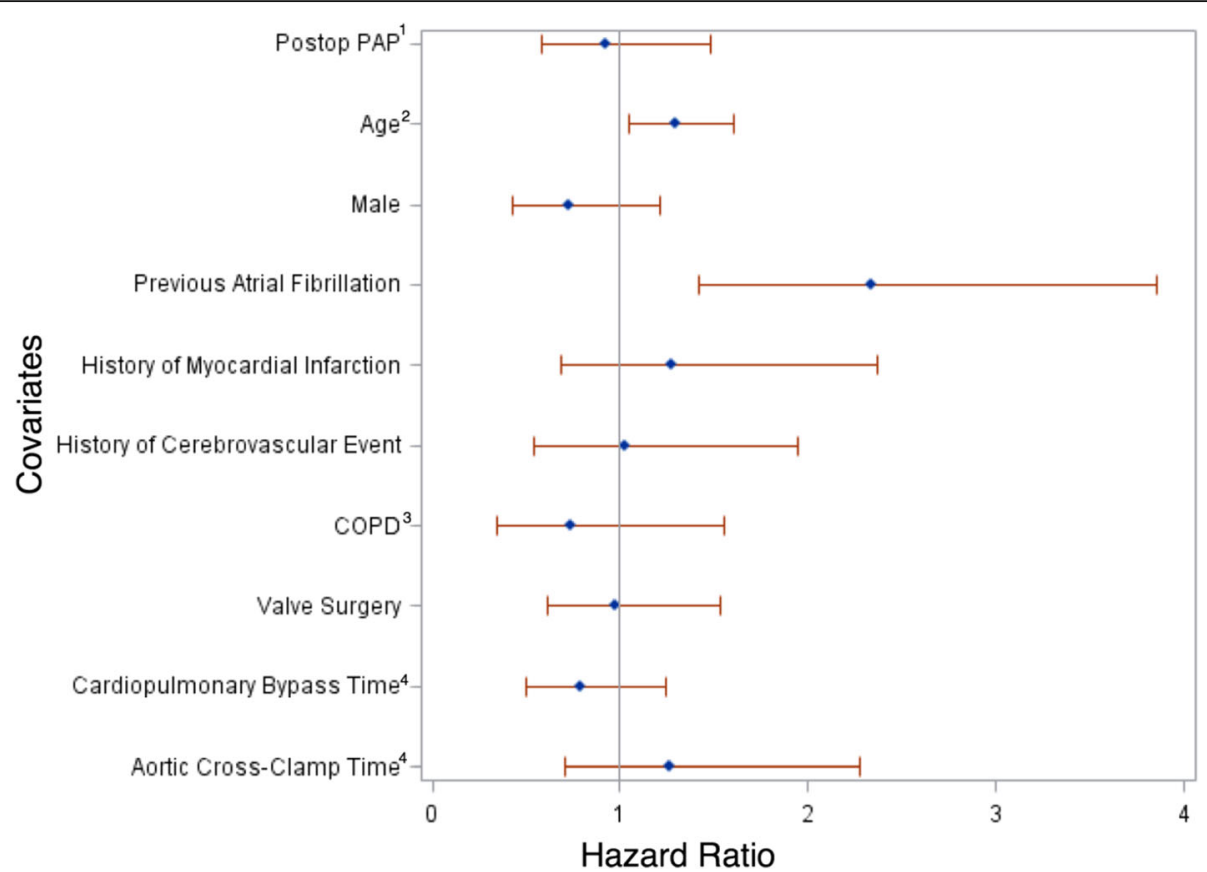

Fig. 3 Forest Plot of Multivariate Cox Regression Model. ${ }^{1}$ We treated postoperative positive airway pressure use as a time-dependent variable in the multivariate Cox regression model. The PAP variable for patients who received postoperative PAP was coded as zero until the start of PAP and as one thereafter. ${ }^{2}$ 10-year increase. ${ }^{3}$ Chronic obstructive pulmonary disease. ${ }^{4}$ 60-min increase

pressure, structural remodeling of the left atrium over time, systemic inflammation, and instability of autonomic tone associated with intermittent hypoxia or hypercapnia (Hohl et al. 2014; Orban et al. 2008; Neilan et al. 2013; Stevenson et al. 2010). In non-surgical OSA patients, PAP treatment reduces or abolishes hypopnea and apnea episodes, reverses cardiac remodeling, mitigates systemic inflammation and reduces atrial fibrillation recurrence risk in patients with prior atrial fibrillation history (Qureshi et al. 2015; Neilan et al. 2013; Xie et al. 2013). It follows, therefore, that PAP treatment after cardiac surgery may reduce the risk of POAF.

In this analysis, we did not find an association between postoperative PAP therapy and POAF risk. One concern is misclassification of postoperative PAP use. PAP use was determined by physicians or nurses' notes rather than objective device adherence data, which could lead to misclassification because nightly PAP use cannot be objectively confirmed. This misclassification may bias the association between postoperative PAP treatment and POAF risk towards null.
Unmeasured potential confounders are another concern. Patients who received post-operative PAP treatment and who did not differed in several baseline and perioperative characteristics such as previous history of myocardial infarction and length of aortic cross-clamp time (Table 1). Although we adjusted for all these measured potential confounders in the multivariate Cox regression model, the concern for unmeasured potential confounders remains. For example, perioperative medication use may differ between those who did or did not receive postoperative PAP therapy, and also be related to POAF risk (Mathew et al. 2004). Other limitations include the lack of OSA severity data and the high correlation between home and postoperative PAP use. This correlation complicates the determination of whether any reduction in POAF risk reflects home PAP use, postoperative PAP use, or both.

Nevertheless, we are unaware of previous studies exploring the effect of postoperative PAP administration on risk of POAF after cardiac surgery in OSA patients. Few studies have investigated the effect of perioperative (preoperative

Table 2 Risk of Postoperative Atrial Fibrillation (POAF) in Relation to Postoperative Positive Airway Pressure (PAP) Treatment

\begin{tabular}{lllll}
\hline & $\begin{array}{l}\text { No Postoperative PAP } \\
(N=76)\end{array}$ & $\begin{array}{l}\text { Postoperative PAP } \\
(N=76)\end{array}$ & $\begin{array}{l}\text { Unadjusted Hazard Ratio }{ }^{\text {a }} \\
(95 \% \mathrm{Cl})\end{array}$ & $\begin{array}{l}\text { Adjusted Hazard Ratio }^{\mathrm{b}} \\
(95 \% \mathrm{Cl})\end{array}$ \\
\hline POAF & $49(64.5 \%)$ & $37(48.7 \%)$ & $0.81(0.53-1.24)$ & $0.93(0.58-1.48)$ \\
\hline
\end{tabular}

We treated postoperative PAP use as a time-dependent variable in the Cox regression model. The PAP variable for patients who received postoperative PAP was coded as zero until the start of PAP and as one thereafter

${ }^{\mathrm{b}}$ Adjusted for age, gender, previous atrial fibrillation, history of cerebrovascular event, history of myocardial infarction, chronic obstructive pulmonary disease, surgery type, cardiopulmonary bypass time, and aortic cross-clamp time 
Table 3 Other Postoperative Complications in Relation to Postoperative Positive Airway Pressure (PAP) Treatment

\begin{tabular}{|c|c|c|c|}
\hline $\begin{array}{l}\text { Outcomes } \\
\text { Categorical } \\
\text { Variables, N (\%) }\end{array}$ & $\begin{array}{l}\text { No Postoperative } \\
\text { PAP } \\
(N=76)\end{array}$ & $\begin{array}{l}\text { Postoperative } \\
\text { PAP } \\
(N=76)\end{array}$ & $\begin{array}{l}\text { Unadjusted } \\
\text { Odds Ratio } \\
(95 \% \mathrm{Cl})\end{array}$ \\
\hline $\begin{array}{l}\text { In-Hospital } \\
\text { Death }\end{array}$ & $3(4.0)$ & $4(5.3)$ & $\begin{array}{l}1.35 \\
(0.29-6.26)\end{array}$ \\
\hline $\begin{array}{l}\text { Code Blue } \\
\text { while on } \\
\text { Telemetry Floor }\end{array}$ & $4(5.3)$ & $2(2.6)$ & $\begin{array}{l}0.49 \\
(0.09-2.74)\end{array}$ \\
\hline Reinbutation & $4(5.3)$ & $7(9.2)$ & $\begin{array}{l}1.83 \\
(0.51-6.52)\end{array}$ \\
\hline Tracheostomy & 0 & $1(1.3)$ & \\
\hline PE and/or DVT ${ }^{a}$ & $4(5.3)$ & $5(6.6)$ & $\begin{array}{l}1.27 \\
(0.33-4.91)\end{array}$ \\
\hline $\begin{array}{l}\text { Renal } \\
\text { Replacement } \\
\text { Therapy }\end{array}$ & $5(6.6)$ & $4(5.3)$ & $\begin{array}{l}0.79 \\
(0.20-3.06)\end{array}$ \\
\hline $\begin{array}{l}\text { ICU } \\
\text { Readmission }\end{array}$ & $4(5.3)$ & $3(4.0)$ & $\begin{array}{l}0.74 \\
(0.16-3.42)\end{array}$ \\
\hline $\begin{array}{l}\text { Cerebrovascular } \\
\text { Event }\end{array}$ & $4(5.3)$ & $2(2.6)$ & $\begin{array}{l}0.49 \\
(0.09-2.74)\end{array}$ \\
\hline Seizures & 0 & $1(1.3)$ & \\
\hline $\begin{array}{l}\text { Initial ICU } \\
\text { Length of } \\
\text { Stay }^{C} \geq 4 \text { days }\end{array}$ & $27(35.5)$ & $31(40.8)$ & $\begin{array}{l}1.25 \\
(0.65-2.41)\end{array}$ \\
\hline $\begin{array}{l}\text { Hospital } \\
\text { Length of } \\
\text { Stay } \geq 10 \text { days }\end{array}$ & $29(38.2)$ & $24(31.6)$ & $\begin{array}{l}0.75 \\
(0.38-1.46)\end{array}$ \\
\hline \multicolumn{4}{|c|}{ Length of Stay as Continuous Variable, Median (IQR) } \\
\hline $\begin{array}{l}\text { Initial ICU Length } \\
\text { of Stay (days) }\end{array}$ & $3(2-5)$ & $2(2-4.5)$ & \\
\hline $\begin{array}{l}\text { Hospital Length } \\
\text { of Stay (days) }\end{array}$ & $8(7-12)$ & $8(6-12.5)$ & \\
\hline
\end{tabular}

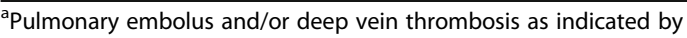
radiographic (including ultrasound) or autopsy

${ }^{\mathrm{b}}$ Intensive care unit

'The period between immediate postoperative care to discharge to telemetry unit, not including ICU readmission days

and/or postoperative) PAP treatment on other postoperative complications but with inconsistent results (Nagappa et al. 2015; Liao et al. 2013). Given the difficulty in reliably determining the postoperative PAP use, the only way to answer this question might be a prospective randomized trial with a clearly defined protocol.

\section{Conclusions}

This is the first study to examine the effect of postoperative PAP treatment on the risk of POAF after cardiac surgery in patients with OSA. We did not find a reduction in POAF occurrence after cardiac surgery in OSA patients given postoperative PAP. However, given the limitations of this study, postoperative PAP should continue to be recommended in OSA patients until future prospective randomized trials with more rigorous data collection can be performed to further clarify this issue.

\section{Abbreviations}

BPAP: Bilevel positive airway pressure; CABG: Coronary artery bypass grafting: CPAP: Continuous positive airway pressure; EKG: Electrocardiography; OSA: Obstructive sleep apnea; PAP: Positive airway pressure;

POAF: Postoperative atrial fibrillation

\section{Funding}

No financial support for this research project.

Availability of data and materials

The data will not be shared because of concerns of potential breaching of HIPPA.

\section{Authors' contributions}

FD contributed to the study design, data collection, statistical analysis, and manuscript drafting. JK-HW contributed to the conception and design of the study, acquisition of data for the work and intellectual discussion of the results. ASW had substantial contributions to the study design, interpretation of the results and critical revision of the work. CAK had substantial contributions to the study design, intellectual discussion for the content and critical revision of the work. In addition, all authors approved to publish the final version of the work and agreed to be accountable for all aspects of the work.

\section{Competing interests}

The authors' declare that they have no competing interests.

\section{Ethics approval and consent to participate}

This retrospective cohort study was approved by our Institutional Review Board. David D Oakes, M.D. was the Chair of the Administrative Panel on Human Subjects in Medical Research who signed the approvals.

The requirement to obtain individual consent was waived because the data were collected retrospectively.

\section{Author details}

${ }^{1}$ Division of Sleep Medicine, Department of Psychiatry and Behavioral Sciences, Stanford Sleep Medicine Center, 450 Broadway Street, MC 5704 Pavilion C, 2nd Floor, Redwood City, CA 94063-5704, USA. ²Department of Anesthesia, Palo Alto Veterans Affairs, Stanford, CA, USA. ${ }^{3}$ Division of Epidemiology, Department of Health Research and Policy, School of Medicine, Stanford University, Stanford, CA, USA.

Received: 16 August 2016 Accepted: 22 December 2016

Published online: 14 March 2017

\section{References}

Ahlsson A, Fengsrud E, Bodin L, Englund A. Postoperative atrial fibrillation in patients undergoing aortocoronary bypass surgery carries an eightfold risk of future atrial fibrillation and a doubled cardiovascular mortality. Eur J Cardiothorac Surg. 2010;37:1353-9.

Hohl M, Linz B, Bohm M, Linz D. Obstructive sleep apnea and atrial arrhythmogenesis. Current cardiology reviews. 2014;10:362-8.

Horwich P, Buth KJ, Légaré J-F. New onset postoperative atrial fibrillation is associated with a long-term risk for stroke and death following cardiac surgery. J Card Surg. 2013;28:8-13.

LaPar DJ, Speir AM, Crosby IK, et al. Postoperative atrial fibrillation significantly increases mortality, hospital readmission, and hospital costs. Ann Thorac Surg. 2014;98:527-33. discussion 33.

Liao P, Luo Q, Elsaid H, Kang W, Shapiro CM, Chung F. Perioperative auto-titrated continuous positive airway pressure treatment in surgical patients with obstructive sleep apnea: a randomized controlled trial. Anesthesiology. 2013; 119:837-47.

Mathew JP, Fontes ML, Tudor IC, et al. A multicenter risk index for atrial fibrillation after cardiac surgery. JAMA. 2004;291:1720-9.

Nagappa M, Mokhlesi B, Wong J, Wong DT, Kaw R, Chung F. The effects of continuous positive airway pressure on postoperative outcomes in obstructive sleep apnea patients undergoing surgery: a systematic review and meta-analysis. Anesthesia \& Analgesia. 2015;120:1013-23.

Neilan TG, Farhad H, Dodson JA, et al. Effect of sleep apnea and continuous positive airway pressure on cardiac structure and recurrence of atrial fibrillation. J Am Heart Assoc. 2013;2, e000421.

Orban M, Bruce CJ, Pressman GS, et al. Dynamic changes of left ventricular performance and left atrial volume induced by the mueller maneuver in 
healthy young adults and implications for obstructive sleep apnea, atrial fibrillation, and heart failure. American Journal of Cardiology. 2008;102:1557-61.

Phan K, Ha HSK, Phan S, Medi C, Thomas SP, Yan TD. New-onset atrial fibrillation following coronary bypass surgery predicts long-term mortality: a systematic review and meta-analysis. Eur J Cardiothorac Surg. 2015;48:817-24.

Qaddoura A, Kabali C, Drew D, et al. Obstructive sleep apnea as a predictor of atrial fibrillation after coronary artery bypass grafting: a systematic review and meta-analysis. Can J Cardiol. 2014;30:1516-22.

Qureshi WT, Nasir UB, Alqalyoobi S, et al. Meta-analysis of continuous positive airway pressure as a therapy of atrial fibrillation in obstructive sleep apnea. Am J Cardiol. 2015;116:1767-73.

Stepnowsky CJ, Moore PJ. Improving CPAP use by patients with the sleep apnoea/hypopnoea syndrome (SAHS). Sleep Med Rev. 2003;7:445-6.

Stevenson IH, Roberts-Thomson KC, Kistler PM, et al. Atrial electrophysiology is altered by acute hypercapnia but not hypoxemia: Implications for promotion of atrial fibrillation in pulmonary disease and sleep apnea. Heart Rhythm. 2010;7:1263-70

Uchôa CHG, Danzi-Soares NJ, Nunes FS, et al. Impact of OSA on cardiovascular events after coronary artery bypass surgery. Chest. 2015;147:1352-60.

van Oosten EM, Hamilton A, Petsikas D, et al. Effect of preoperative obstructive sleep apnea on the frequency of atrial fibrillation after coronary artery bypass grafting. Am J Cardiol. 2014;113:919-23.

Wong JK, Maxwell BG, Kushida CA, et al. Obstructive sleep apnea is an independent predictor of postoperative atrial fibrillation in cardiac surgery. J Cardiothorac Vasc Anesth. 2015;29:1140-7.

Xie XM, Pan L, Ren DQ, Du CJ, Guo YZ. Effects of continuous positive airway pressure therapy on systemic inflammation in obstructive sleep apnea: A meta-analysis. Sleep Med. 2013;14:1139-50.

Yadava M, Hughey AB, Crawford TC. Postoperative atrial fibrillation: incidence, mechanisms, and clinical correlates. Cardiol Clin. 2014;32:627-36.

Zhao L-P, Kofidis T, Lim T-W, et al. Sleep apnea is associated with new-onset atrial fibrillation after coronary artery bypass grafting. J Crit Care. 2015;30: 1418. e1-5.

\section{Submit your next manuscript to BioMed Central and we will help you at every step:}

- We accept pre-submission inquiries

- Our selector tool helps you to find the most relevant journal

- We provide round the clock customer support

- Convenient online submission

- Thorough peer review

- Inclusion in PubMed and all major indexing services

- Maximum visibility for your research

Submit your manuscript at www.biomedcentral.com/submit

) Biomed Central 